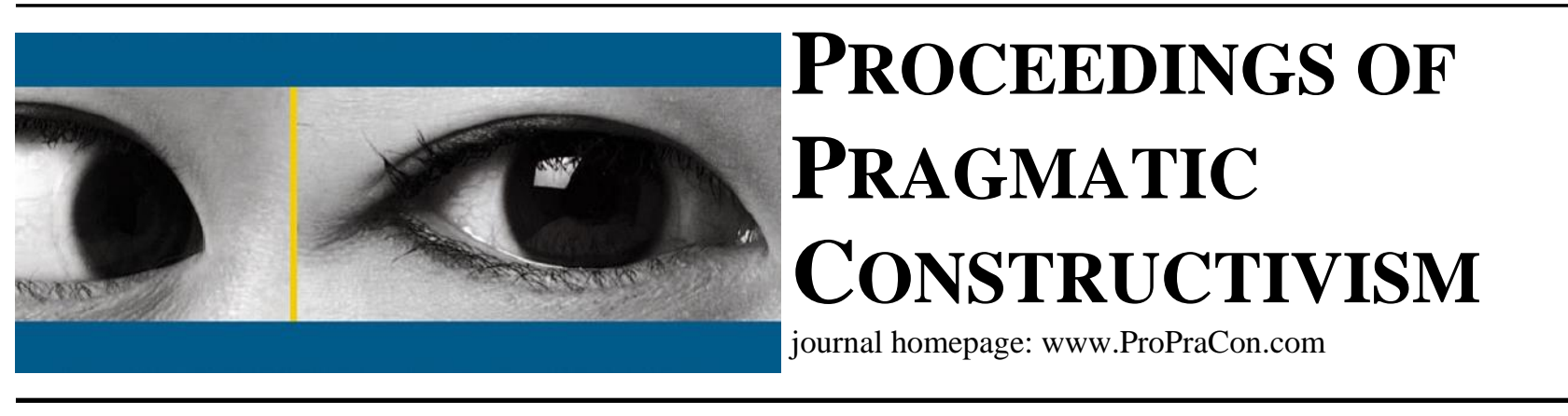

\title{
A Pragmatic Constructivist Perspective on Language Games
}

\author{
Lennart Nørreklit \\ Professor Emeritus, Aalborg University \\ philosophy-house@gmx.de
}

\section{Introduction}

This article analyses the workings of communicative practice in the construction of reality from a pragmatic constructivist (PC) perspective. The point of the PC perspective is to analyse the principles with which we successfully construct a world that also enables us to achieve a future (for introduction to PC see Nørreklit, L. 2014, 2011 or 2017). This article illuminates the workings of the PC framework from the communication dimension point of view. It uses Wittgenstein's idea of a ,language game' (LG or ,game' for short), to outline the workings of the communication dimension (Wittgenstein 1953).

Section 2 outlines the idea of actors and reality construction including LG as the social factory and the basis of division of labour, which also outlines a basis of social ethics. The main points are summarised in the two main ideas of PC, namely integration of the four dimensions (fact, possibility, value and communication) in figure 1 and the being in the world as the actor-world relational construct in figure 2 see also Nørreklit, L. 2017). To illustrate the workings of LGs I construct a simple LG, the Apple language game, that is used repetitively in the article.

Section 3, on illustrates the workings of integration through different conceptions of meaning: the overall Wittgensteinean notion of meaning as use, meaning as reference, meaning as basis of thinking. It then discusses the process of understanding which we reinterpret to consist of a ,double loop' in order to reflect the actor's relation to the world she is trying to understand. This illustrates the basic relational character of PC and the importance of this being adequately reflected in the communicative practices.

The article finishes with an appendix on ethics, which illustrates how the problems of a classic reductivism; namely, Hume's guillotine, which separates ethics and rationality and makes the factual world work without ethics, is overcome through integration.

\section{LG and Reality Construction}

\subsection{The Apple language game (ALG)}

To illustrate our points, we need a specific LG. Our language game of choice - call it the Apple language game or the Apple-game for short - is inspired by the first LG Wittgenstein presents (Wittgenstein 1953 §1). However, while Wittgenstein uses his games to make philosophical points, we use it to illustrate how LGs function and construct human reality as perceived from a PC point of view.

In the Apple-Game a mother asks her boy to go and buy 5 red apples at the grocery. She gives him a sheet of paper on which she has written „5 red apples“, which he is supposed to give to the grocer. After this we can imagine different things happen. We imagine an ordinary friendly setting - typical for Wittgenstein's LGs. The boy goes to the grocer, buys the apples, goes home and gives them to his mother. The game demonstrates that social values of care and 
friendliness characterising the environment. If the actors had no language, not even such a simple game could take place. The LG is the human way of life.

The game has a small plot with three actors. It is - prima facie - about buying things and about a parental endeavour of the mother raising her boy. Although it is minimalistic, it is of course already complex. The integration of facts, values and possibilities needed to succeed according to PC are illustrated as follows: The game takes place in a complex environment of a minor city with many other anonymous actors playing many other LGs. These are the factual conditions our actors are acting in. To understand the game, we need to understand how the values and possibilities are entwined. Simply put: The mother wants to make a desert and needs 5 apples. This is a part of the value dimension from her perspective. The city with its grocery provides the resources necessary and thus the general possibilities for people who live there. One just needs to go and pick up the resources - and pay for them. The payment is part of the value perspective, from the grocer's perspective. The analysis of possibilities from the mother's perspective might be as follows: the grocery is nearby, and the boy knows the way, he is also not afraid of talking with people, so he can easily tell the grocer that he wants to buy 5 apples. For security reasons I have given him the sheet.' The motivating values for the boy may be the excitement of trying to go shopping on his own. Also, he appreciates the friendly words and praise from his mother.

The actors use plenty of knowledge, which presupposes previous learning, which also occurs in LGs. Given the knowledge of relevant possibilities and values, as well as the acceptance of relevant values, the boy will go and get the apples, and the LG is finished successfully.

\section{Figure 1: Reality as a 4-Dimensional Integration}

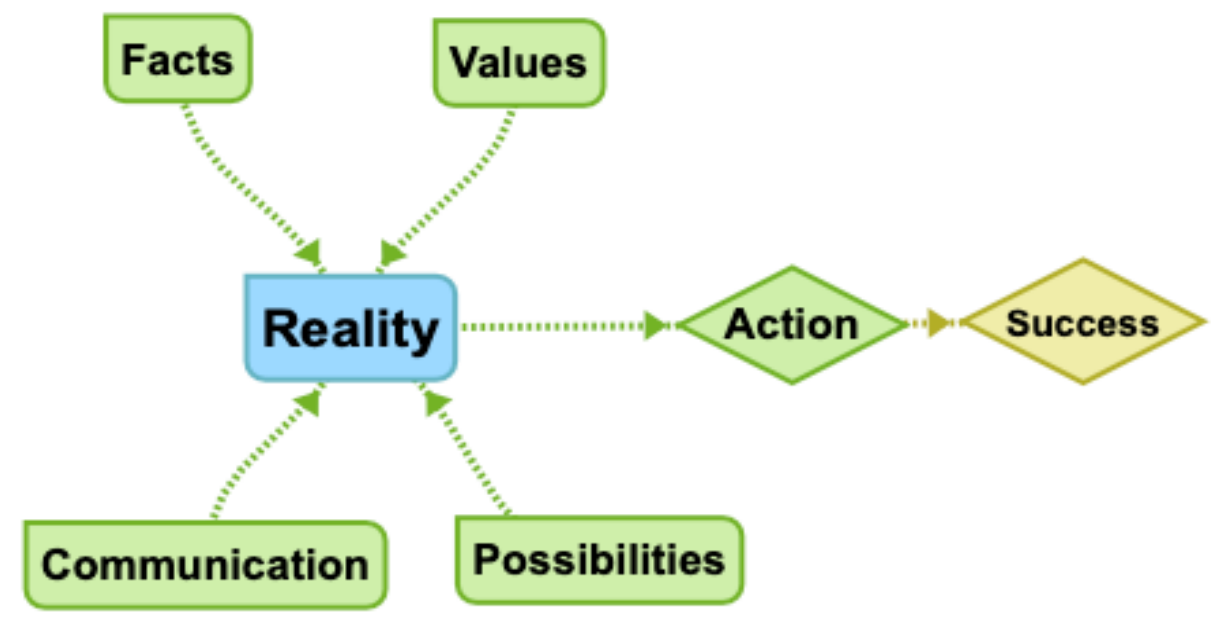

\subsection{The Language Game}

Human life combines activities with communicative activities in a way that no other living beings on planet Earth are able to do. In no other species can a mother tell her offspring to go buy 5 pieces of food.

This way of life enables us to work together in increasingly complex ways and achieve the most advanced things, which produces a reality unimaginable to our ancestors. The language we use in this process can mostly be produced at will - only a few signs of our body language are difficult to control. We learn to produce and use words and signs and we have the skill and creativity to invent new words and signs as we go along ad infinitum. This makes it easy to model and re-model and thus improve our ideas of the world over and over again. In this way we develop our ways of doing things, integrate new inventions and produce new technologies. The language is not there a priori. We make it exist as we produce it. Using it enables us to develop and change the world.

Interactive activities are organised through LGs. In an LG people’s activities are coordinated by communication. Communication and action are entwined in many ways. People engage in countless LGs. The games are nested and controlled in many ways to structure our activities and organise life. 


\subsection{Language Play}

In a world focused on development and change, LGs of learning and creative innovation are necessary in all practices, especially in research practices because they are supposed to provide an innovative basis for the emerging LGs and practices of the future. Thus, research should be managed by advanced insight into the LGs of research in order to avoid being controlled by biased interests as opposed to interest in truth and concerns for the future.

To a certain extent learning and creative innovation takes place in special LGs like those of parent-child or teacher-pupil, in research seminars, or by publication in scientific journals. Other learning is entwined with operative LGs. However, research is a place where the creative and innovative are the operative.

A special feature in creativity is the recurring need to turn off the rules of the game. LGs are very much based on rules. These rules must be produced and analysed before we can use them. After they have emerged, we need to test if and how they function and whether they can perform the intended job or not. To proceed and develop new rules which replace old or deficient rules, it is necessary to drop the existing rules and instead engage in language play. This play enables actors to work out new ideas that can be tested and used, as such rules enrich our understanding and productivity with new LGs in practice.

\subsection{Reality construction}

Our ,being in' the world is an intertwined set of relations. They include our being in space and time, and they include the phenomena of knowledge, values and meaning. The relations are physical as well as social. As actors, we learn to control or at least influence most of these relations. If we do not want to engage in them, most often there are ways to withdraw from them. The relational complex is therefore a construct and the actor is an important constructor both of and in her reality, i.e. the way she conceives reality and acts in it. Our conception of reality is a cognitive structure. Each actor has her own specific reality construction which, however, is entwined with that of other actors in a common social conceptual structure. For instance: The actors in our game live in a city. This is the general framework. Relating to the city involves developing many relations and relevant skills concerning work and social relations. In the Apple-Game the mother knows the general spatial lay out of the city and has some ideas how it is evolving. She is training the boy to relate to various types of actors and thus the functions of the city. The boy has a very different conception of the city than his mother. It is the place and time from which everything comes: people as well as things. To the grocer, the city is, among other things, the living place for himself and his customers and he hopes development will give him more customers.

A reality construct would not exist without actors participating in it. If the mother, the boy and the grocer didn’t exist then our LG would not exist. An actor may be driven by habits or social heritage, or by force or other innovative processes - however, the construct would not exist without the actors engaging in producing it. The mother may behave as her mother once did, or she may have read about how to raise children in a psychological handbook. Likewise, the grocer may have learnt the business from his parents, or he may have taken classes in business at a college. In order to engage in the common relational construct, the actor needs adequate knowledge, values and understanding. Her knowledge, beliefs and cognitive skills are how she moulds her relational interaction, and her life and successes depends on them. They are the very reality, which the actor constructs - in cooperation with and response to her conditions. Her success depends the degree of adequacy with which she is able to conceive the world she lives in. Everything she does influences her relations. Everything she learns influences her ability to mould the relational complex in which she lives.

The relational complex makes up her reality: it positions her in the world socially as well as physically, it characterises her skills and possibilities, her understanding and values. The relational complex constitutes her knowledge, understanding and attitudes about the world, including herself; and it encompasses the phenomena in the world, which she relates to. Thus, both her perception of the world as well as her skills to act, influence and change it are involved in the relational complex. This complex is organised in a conceptual framework that guides her understanding and actions. As a living being, she is an actor. She engages in forming and influencing the relations, and her life is based on her actions and the choices she makes. She is able to influence almost any aspect of her relations in

life, strengthen them, weaken them, leave them - and produce new relations. In our exemplar the mother is involved in a relational structure as a mother in the city. She can change her relations: If she does not like the city, she can move. Supposing she has a job, she can quit her job and try find something else. She can even change her relation of being a mother by putting the boy up for adoption. Some people even commit murder to change their relations, including committing suicide. 
The degree of success in thus influencing her reality through her activities depends on the adequacy of the framework. Its adequacy is the degree to which it correctly represents the world. If her perceptions deviate from the world, then her activities become incapable of being successful. For the most part, her errors can be corrected within her cognitive conceptual framework. To do this she needs a notion of the world that she can trust and that is not hampered by illusions or paranoiac imaginings. However, if it is the framework itself that is inadequate, then she becomes unable to detect and analyse the errors, because her method to detect errors is affected by the problem. The framework produces errors even when she is looking for them or aware of them. Then she may live in an imagined world that does not exist, i.e. that is very different from the world that we live in, and she may be unable to come out of this world like a dream she cannot wake up from. Her visions and her actions become fictional and seemingly incomprehensible.

Figure 2: Reality as Actor-World Relational Complex

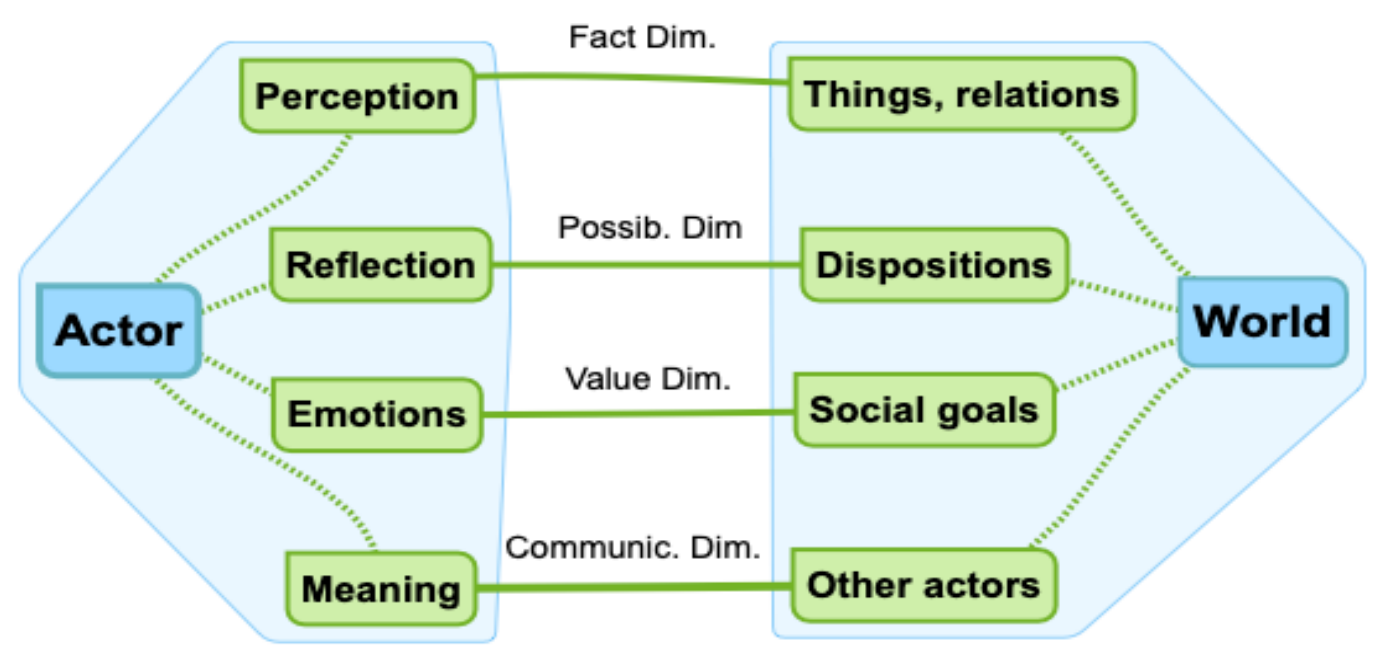

\subsection{Conceptual frameworks and inherent problems}

Although communication itself is an activity, we need to distinguish between communication and action. Communication is about conveying a message to the other. Action is about producing a change. The communicated message may reflect actions and their conditions and consequences realistically, but they may also misrepresent actions, their consequences or conditions. This leads to actions producing effects other than the intended ones. This happens when the conceptualisation of the world that is used in our reality construction is inadequate.

Conceptual frameworks in use in reality construction usually have some inherent flaws, which the practices cultures, traditions, even scientific traditions - tend to reproduce, although scientific work has the potential to eventually overcome its inherent flaws.

The adequacy of the framework is thus defined pragmatically as the ability to produce successful acts. In our example, we can imagine various delusions. For instance, if the boy has been told scary stories about zombies disguised as people, he may imagine the grocer to be a zombie, which may influence his behaviour. On the social scale, the faulty conceptual constructs that produce major social problems, may prove very difficult, even impossible to correct.

The flaws cause the operations to produce negative side effects that accumulate to major social problems. Almost all of the problems of modern society are produced by human beings because the conceptual framework in use is inadequate and therefore produces negative side effects - be they climate, pollution, crime, war, migration, extinction of species, bacterial resistance to antibiotics, etc. These problems are all produced by human beings due to unseen effects of our practices. The effects are unpredictable either because we didn't have the relevant knowledge - and only scientific knowledge can re-conceptualise our framework to overcome these problems - or because social control of practice actually prevents the use of our knowledge, which makes it a political problem.

Often the problems are not inherent in the basic conceptual structure but in the usage of the framework. The usage is often controlled by short term interests and thus neglect long term consequences. Thus, there is a control structure amongst the LGs: For instance, excessive use of antibiotics produces resistant bacteria. Nevertheless, the 
excessive use continues. Practice may be more concerned about short term gains than long term risks and losses. To solve the production of the problem one must analyse and re-conceptualise the controlling game. Often the attempts to solve a problem do not address the root cause. The problem is located at an action-oriented level, whereas the root cause lies in motivating factors in a higher level game, which may render the action-oriented solutions ineffective. One needs an analysis of the interplay between the games to identify the culprit.

In order for science to contribute to the needed re-conceptualisation of practice and to transform practices to overcome inherent problems, it must be independent and not controlled by special interests that have other priorities. Only independent scholarly research can - sometimes - re-conceptualise a framework to overcome inherent conceptual traps.

\subsection{Pragmatic or Social}

The LGs of the actor position her actively in a social world. She uses communication abilities that match those of her co-actors. If mother, boy and grocer do not understand each other the game cannot function. The players understand the game if they are able to play it, i.e. we use pragmatic criteria: If in the Apple-Game the boy does go buy the apples, then the mother and boy understand each other. If the grocer sells the apples to the boy, then they understand each other.

Games involve several players by design. A player may of course play a game with herself in a form of training by simulation. But this presupposes that she is able to pretend to change her role during the play so that she successively plays the different roles involved.

Games are pragmatic constructs. The interaction should make it function. The basic pragmatics of the game is intrinsic, namely the functioning of the interplay between the actors. This is, so to speak, the efficiency of the game. In a wider context, the game has an extrinsic purpose and the pragmatics of the game are concerned with the fulfilment of that purpose. This is the effectiveness of the game. Performance evaluation should address efficiency or effectiveness. It is a mistake to focus on efficiency. That tends to produce an ineffective social structure. No matter whether one concentrates on intrinsic or extrinsic performance, smooth mutual understanding of the actors, i.e. effective communication, is essential for the performance. The intrinsic efficiency of the Apple-Game is about getting the apples. The extrinsic effectiveness is not directly part of the game, but it could be. For instance: when the grocer chooses the apples, he may face a choice between several types of red apples. Thus, he may ask the boy what the apples are to be used for. Now the game would profit from the boy knowing the extrinsic purpose. If the boy says: „They are for making apple-pies, “ then the grocer has a lead to make a good choice that supports the effectiveness of the game.

All LGs have a communicative and a physical side. Sometimes the communication concerns physical matters only. However, reports, grades, laws, treatises etc. are social, symbolic constructs that are produced by communicative acts. They exist because they materialise in physical phenomena - sounds, papers and/or electronic data that have the adequate social status. If they do not have this status, then they are fake - using them will be rejected if discovered by social authorities.

However, the material constructs resulting from human interaction comprise all our physical products. An architect's drawing of a house is a symbolic representation, but the house is more than the drawing. People may live in the house, but not in the architect's drawing. The reality of the house does not depend on the social status, but on whether it actually stands in the physical world which is proven by the pragmatic functioning.

That something is a physical construct does not mean that it is not embedded in social constructions. For instance, the uses of a house are regulated by the city planning. Thus, most physical constructs are embedded in a web of social constructions regulating their use. For instance, to return to the example LG, the sales of apples may be regulated by restriction on the use of pesticides in their production.

\subsection{Reality and world}

World' is an inclusive or comprehensive concept: everything is in the world. Nothing is outside the world. This includes everything: every relation, every actor, every phenomenon; it includes everything which is real as well as all imaginations of the unreal - but it does not include that which is unreal. Everything in the world is there, whether we accept it or not, whether we know it or not, whether these things are human constructs or natural phenomena or both, whether or not they are symbolic expressions. Symbols exist in the world even if that which they symbolise does not exist. This is a realistic foundation.

The world as we know it appears to be dominated by analogue features, i.e. features that have no sharp borders. Everywhere we find gradual transitions. The transitions are gradual both in time and space. This makes it difficult to define the concepts precisely. Therefore, our concepts tend to have vague borders, as the phenomena in the world have 
vague borders. Sharp borders seem to be arbitrary. When, for instance, the boy counts apples, then we are dealing with distinct units. One can find out if he brings 5 apples home. However, if the mother wants the boy to be home before it rains or before darkness, then the advice is vague and may be interpreted differently by boy and mother.

Reality ' is, on the other hand, an exclusive concept: we distinguish between that which is real, and that which is not real but only imagined. An imagination is real, it exists, but that which one imagines may or may not exist. The difference between real and not real shows itself in pragmatics. Unexpected failures and loss of control indicate that we imagined something that was not real. The difference between real and not real is pragmatic. Illusions lead us to doom and leave us in need of help.

While many analogue phenomena in the world also appear as analogue phenomena in our reality construct, we produce many reality constructs of an either-or nature, i.e. a digital nature, although the corresponding wordly phenomena are analogue. We make such constructs because we need them, although we know that they may be considered as somehow misrepresenting the world. But that 'criticism' is missing the point. One reason for needing them is that we need to make decisions to determine what to do. We face choices, such as: „shall I act or not?“ or „shall I move right or left?“, „shall I use an umbrella or not?“ etc. Here the decision is an either-or structure. This digital either-or is forced upon us as soon as we consider doing something. As long as we only look at the raindrops falling, we do not need to make a decision whether this is rain or only a few droplets. The analogue structure of the world mirrors our reflections of it in the vague concept of rain. But when we want to go out, then we must make choices: shall I take an umbrella or not? Shall I go right or go left? etc. I may choose automatically by habit or I may need to reflect a little before I choose. But if we cannot choose, then we have lost control over our actions. Thus, in order for a person to be an actor, she needs to make fuzzy mergers between the analogue and the digital in her reality construction. The fuzzy merger does not truly reflect the worldly analogue phenomenon, to which the actor relates herself, because this phenomenon has no sharp border. But it reflects the situation of the actor in the world.

The analogue-digital problem is a classical problem in logic where a divalent (digital) logic challenges multivalued logics. The problem is also known in methodology and accounting and especially in technology. In logic, the digital point of view means that a statement is either true or not true - the digital either-or. Those who do not like sharp logic object that the world is not like that. And they are to a large degree right. The world is analogue. „Either it rains or it doesn't rain“ simply cannot reflect the situation of the world and this brings us close to forsaking the classic laws of logic. The consequence is a breakdown of all recognition. If we do not resolve this dilemma, then we find our research swimming round between scepticism and fluffy postulates. In various papers and conferences, a post-truth world or outright rejection of facts seem to be common.

The PC distinction between world and reality dissolves this problem without falling into these absurd traps. It does not give in to post-truth fantasy nor does it accept fundamentalist rigidity.

The case with rain is clear and simple: „is it raining, or isn't it raining?“ is a digital question. In our way of constructing reality we need such questions in order to make decisions such as whether to use an umbrella or not. One cannot use ,more or less' of an umbrella. In the physical world there is, however, no sharp transition between whether it is raining or not. Only gradual transitions exist. It is analogue. There is no either-or concerning whether it is raining or not.

There are many types of borders in the world. They do, however, always turn out to be analogue rather than sharp. For instance: There is the border between land and sea. Either we are on land, or we are on the sea. On the map, the border looks clear and sharp, as an either-or, as digital. However, the sharp borders are human constructs. They do not exist in the analogue world. When people stand on the beach, they always see that the water is moving and there is no sharp border between land and sea.

In technology we have experienced a transition from analogue techniques to digital techniques. For instance: the old fashioned LPs, which are analogue, have been replaced by modern digital representations of music. A similar shift has occurred in imaging: old fashioned chemistry-based analogue imaging has been replaced by digital techniques although photographers still exist who swear that the classic analogue techniques produced better images because the digitalisation has removed the subtle transitions.

There is no chance to represent the complexity of the world in its entirety because it is analogue. It is infinite. Our languages have only a few thousand words. Furthermore, we need to distinguish between right and wrong, true and false - that is to say, we need to apply a digital perspective, otherwise we cannot draw conclusions and make decisions. To help us operate digitally, we develop criteria, for instance, the minimum size of the water droplets, the amount of water purring down per minute, or other measurements. Such criteria may seem arbitrary compared to the analogue world, but they may be designed to help make specific decisions. For example, the criteria for when to use an umbrella differs from the criteria used to make decisions about when to sow or when to harvest.

But even measurements according to specific and precise criteria are imprecise and represent a variation, i.e. something analogue, which we cut away. Not even a true geometric straight line can be found in the word. It is a cognitive construct. Improvement of control is often a question of constructing a more sophisticated structure of measurement over phenomena that are analogue. 
This does not mean that the world does not have any non-arbitrary digital, countable, units. People, books, chairs, etc. are just some perfect examples. A person is there, or she is not there, she exists or does not exist.

In mathematics the natural numbers used for counting represent a digital world. Real numbers representing continuous quantities represent the analogue world. Ultimately, however, world seems to be digital, because it has a smallest unit: the quantum. But that is so far away from our perception that we disregard it and maintain the idea that the perceived world is largely analogue. Of course, this world is itself a perceptual construct. Its analogue character means that it transcends our conceptualisation.

\subsection{The Social Factory}

The life in LGs is not only the way we run our institutions and make our products; it is also the human social factory. It not only teaches us practical and theoretical knowledge and skills, it makes us become social beings in general and the specific games we play make us special. It moulds our attitudes towards other people, our social character and our preferences. It makes us friendly, trustworthy, reliable and ready to help others in need. It produces our social ethics - how we treat and perceive others, and how we try to make others perceive us. Deficiencies in our life in LGs make us become less social. Everything in which we are engaged in through our LGs becomes a part of our story, changes us and becomes a part of who we are, our character and identity.

Our successes in practice depend on our abilities to play our games successfully - that we have learned and practised them, and that we are masters of the games we play. The games we play form our life and career. We live from LG to LG and our choices and skills in doing so produce our life. One LG connects to another and we become interconnected with other groups of games that constitute a social practice, which is related to the society we live in. Fundamentally, by engaging in our LGs we make ourselves part of the history of mankind.

The social factory teaches us how to make our brains work simultaneously for the social whole and for the individual participants. In a successful LG a participant is concerned with the other actors as well as the success of the whole game. For instance: The mother is concerned with her boy: „Does he understand me?“ „Does he remember the way?“ „Will he come home early?“ The grocer is concerned with the boy: Putting the apples in a little bag he hands it to the boy and asks him if he can carry it, and whether he can find the way home. And the boy shows his concern for the mother when hurrying home. They are also concerned about the whole, although they see different wholes. For instance, the boy may be concerned that the mother gets the apples in time to produce the desert. Suppose there were problems: the boy cannot find the way, or the mother gets too nervous while waiting so she starts going looking for the boy before he is home - then our priorities change! A lot of new LGs are quickly installed to come to the rescue. Here the concern for the individual boy overrides her concern for the overall success of her apple-desert-game by instigating urgent search games.

The considered, calm and harmonious course of a LG is an ideal for cooperation. There are many ways in which games can become disharmonious. This article restricts itself to the ideal, where the social interactive atmosphere is calm and friendly and the communication and interaction between the participants flows smoothly without any quarrel.

\subsection{Division of labour and the basis of duties}

Living and using LGs also produces the division of labour, which includes our skills and attitudes towards the division of labour, or how one accepts and learns a specialised role in a game and how one is obliged to carry out the duties it implies.1 Entering social life and participating in interaction is based on mutual trust that the others fulfil their role in the division of labour. This is the origin and legitimation of all duties and obligation. LGs are cooperative, they shape all aspects of work ethics, including the role of friendliness, diligence, care and concentration, the importance of keeping promises, trustworthiness, accountability, the importance of helping others and forgiving, and the importance of acquiring the necessary skills. Through LGs we learn all the qualities that are important for cooperation in practice and for becoming successful, appreciated and getting a good life.

Messages concerning what one must or ought to do must be based on a reason. The questions: „Why should I do such and such?“ or „Why should I learn this?“ demand answers. Otherwise they are not justified and should be dismissed. A claim that someone must / ought / should do something is meaningless unless there can be a reason why she should do so. Statements on one's duties and obligations must be based on a reason.

Thus, obligations presuppose LGs that provide reasons. However, the opposite is also true: all LGs presuppose obligations or duties. No LGs would exist if there were no obligations. Each LG operates through a distribution of

\footnotetext{
${ }^{1}$ This is how the theory of LG enables a solution to overcome the is-ought gap in ethics. For more, see the appendix.
} 
different roles where each player is different. To enter an LG is to accept the obligation to play the role. And for the players to accept a new member is to accept that they have a duty to play their role with the others as co-players. Thus, they all have expectations as to what they themselves must do as well as what the others are doing, and these expectations are based on the supposition that everyone has accepted the duty to play their role. Without this mutual duty-expectations relationship, a game would not exist. The credibility of a person concerns her commitment and skill to fulfil her duty in fulfilling her role.

In the Apple-Game the boy is still in the process of learning how to participate in LGs. The mother considers herself a mother, plays the role of a mother and thus she has committed herself to fulfil that role. She has taken the obligation to behave as a good mother upon herself - the boy's development depends on it. He must, for instance, be able to trust his mother that she will not ask him to do something bad. Also, he must trust the grocer to choose good apples and that he does not cheat by overpricing. The responsibility for an adult to help the child is not restricted to the mother and the grocer. All adults have a duty to help the boy if, for instance, he lost his way. This obligation is part of participating in the LGs in society as an adult.

The actual division of labour and thus the duties of the actor are determined by practice, and thus partly determined by the structure of the society - for instance, in the apple-game, the mother-child relation, and that there is a grocery where one can buy fruit. The structure is an entwined cognitive-physical structure, i.e. it is based on physical realities and cognitive-communicative interpretations corresponding to the entwinement of communication and action in the LG.

There are duties involved in any division of labour: the doctor is obliged to treat patients, and society has helped her become a doctor in order to treat patients. Division of labour is socially accepted precisely because the specialists are expected to help people with their specialised knowledge. By specialising in a certain direction and making it one's job, one has a duty to use the expertise to serve other people in society.

\section{Meaning}

There are two types of theories on meaning - the theories about meaning of life and the theories of meaning about words and other symbols. Considering how different the two types of theories appear, one might wonder how they concern the same concept. In the section on meaning the main focus is on the linguistic side, i.e. words and symbols. In the following section on understanding we will see the connection between the two sides. Let us consider it meaningful to assume that they do concern the same concept. Thus, there should be something connecting the different approaches: The idea is that there is an overall human perspective through which things have meaning. Without this, things in smaller details in life lose their meaning. When we analyse the meaning of a message, say in an LG, ultimately, we need to understand its role in the larger whole of life. For instance, in the Apple-Game we do not understand what is going on if we do not understand the need for food, the mother-child relation or the division of labour in the economy.

\subsection{Meaning is Use}

Expressions (signs and words) per se are physical phenomena. They have causal properties. Besides being a witness of their causal heritage, a prediction of their effects, and having special aesthetic qualities, there is nothing in them, physically. What makes them interesting and enables them to produce communication is the meaning they convey in the situation they are used.

Meaning is use according to the late Wittgenstein (E.g. Wittgenstein $1953 \S 43)$. This implies that expressions can be more or less understood or misunderstood. The meaning is traceable in the LGs they are used. Expressions can be used for almost anything needed in communication. There is no primary or basic use.2 Any use will do. One may use them to make descriptions, predictions, promises, give advice etc. etc. We consider various important candidates for primary usages: communication, messaging, PC-based integration, reference, and thinking.

Communication and messaging: Without communication no LG, no coordination of work and thus no practice would exist. How coordination and division of labour works is illuminated in the LGs. The meaning of the communicative acts is to convey specific messages to other actors to enable the game to continue going and achieve its goal.

\footnotetext{
2 The very concept of LG as life form and as illustration of the meaning seems to imply that the use of language to play games - i.e. the communicative practice - is the primary use of language. Thus, the concept LG may hint at an element of inconsistency in Wittgenstein's theory, that there is no basic or primary usage - because the primary usage is communication in LGs.
} 
The game takes place within the framework of a reality construction. It does not exist in a vacuum. It is this framework that enables the LGs to construct and convey specific messages between the participants.

For the LG to function smoothly, it is necessary that the actors communicate freely. Only then can they use communication to identify problems, overcome interpretation issues and adjust their actions. This guarantees high effectiveness of practice.

In a culture where free speech is restricted, LGs also become restricted. Language loses its intimate connection to understanding, and the actors cannot smoothly adjust and correct misunderstandings or solve interpretation problems. The result is the emergence of problems and tensions.

It is important to be aware that a game may have more than one use. It may appear to have one function but in reality, it may serve other functions. Each actor in a game has her own purpose, and the game thrives from the ability of cooperation to satisfy multiple purposes. Thus, an expression may give several different messages simultaneously.

Information: Communication as messaging does not mean that language is just an information system and that the meaning of words and symbols is information. There must be a point and relevance of the information for it to have meaning. Loads of information, big data per se, is just descriptive information, not meaning. It can only get meaning through its use.

\subsection{Integration}

In a PC analysis of meaning there must be a special focus on the integration because it enables enactment of activities and activities to succeed. Without integration, communication becomes meaningless and the messages of the LG are unable to serve their purpose of triggering other actors' successful activities. It is this communicative ability of the messages that constitutes their meaning. In our Apple-Game the mother hopes to trigger a successful activity by asking the boy to buy 5 apples at the grocery. The boy hopes he triggers a successful action of the grocer by saying: „5 red apples.“ By saying this he does not simply mean „,5 red apples.“ That would make no sense. He means that he wants to buy 5 red apples. It is implicit in the meaning of a message that it calls for complementary activities necessary to finalise the integration that constitutes a successful act. More specifically: The message calls for that which is missing in the integration for the desired effect to be produced. This is the meaning. This is how communication steps in and enables the actors to materialise the integration that make actions succeed.

How is integration possible? With such different types of phenomena - facts, possibilities, values, communication - how can they be integrated? For one thing: there is a principle of connection in time and space. The phenomena are attached to and connect things in the world that thus become connected. Facts, values (goals), possibilities and communication take place in an interconnected time and space. When facts and possibilities form factual possibilities, then they are locked together in time and space. For instance: I walk, I tell a story, I dance etc. may be facts at a certain place and time. However, I can walk, I can tell a story, or I can dance, are possibilities that I have. As long as I have the necessary skills, then the possibilities are , with me‘. The factual possibilities are where I am. The same applies to values and goals. If dancing is a value to me, then the value ,is ' where I am when I am dancing. It is not somewhere else. The values and the possibilities they realise are where I am. Modern technology has widened the space-time reach of factual possibilities.

Sometimes a LG cannot not work as its communicated content presumes. Sometimes it is the beginning of a practice although the conditions for that practice do not exist. For instance, a swindler or a spy may pretend she has a background that does not exist and to get access to games he is not qualified to access. A manager may, for various reasons, make employees organise strategic plans although she has neither resources nor intention to implement them. A lover may promise her loved one things, she has no intention to fulfil.

The PC analysis of reality construction claims that the integration of the four dimensions in the actor-world relational complex (the factual, possibilities, values and communication) constitute the sufficient condition for activities to succeed - thus, the risk of an undertaking is caused by insufficient integration. The argument for this is as follows:

- Factual knowledge: Actions need to be based on knowledge of the actual state of affairs. If for instance, if the boy goes to the grocery without factual knowledge of the road, he may lose his way. If an actor acts without knowing for instance her financial resources, the regulations, the skills of the people she cooperates with etc. then she runs an enhanced risk of failure.

- Possibilities: The actor also needs to know what possibilities that are embedded in the factual basis - she needs to know if her project is technologically, financially, or politically feasible, and not only that, she needs to know that it is possible for her to finance the project, have the technological skill, and obtain the political support needed. In other words, the project must be possible, and the possibilities must be integrated with her factual basis, so that it is an actionable possibility for her. If this is the case, then she is almost in the driver's seat: the project can be done, and she can make it succeed. 
- Values: However, from the fact that something is factually possible for somebody does not mean that that they can do it. They also need the motivation. The motivation comes from the goal of realising their values. Given the factual possibilities, the realisation is only a question of whether the motivating values are strong enough. If the actor's values are outside the range of the possibilities, then the action will not succeed because that which is possible is not considered sufficiently valuable. Thus, values must be integrated with the factual possibilities for all actors concerned in a project.

- Communication: Since this understanding can only be achieved by communicating the message, and since the actions can only be realised in the cooperation facilitated by the relevant LGs, we conclude that communication needs to integrate values, possibilities and factual basis. This condition is necessarily fulfilled in functioning LGs. Integration defects produce at weaknesses in the function of the operating LGs.

Consider the Apple-Game:

Factual dimension: Both mother and the boy must have factual knowledge such as where they are, where the grocer is and how to get there, what 5 red apples are, and so on. If none of them know the way to the grocer or what a grocer is, then the game fails.

Possibility: The mother needs to know, for instance, the distance and complications to go to the grocer and that the boy is capable of going there, orienting himself and finding the store. The factual basis and the possibilities are interwoven - i.e. they are integrated.

Value: Also, the mother needs to motivate the boy to do the job - and he has to trust her. How she does that depends on her knowledge what motivates him. She may for instance reward him - by praising him as a good boy knowing that this motivates him.

Communication: And finally, for the activities to unfold and succeed we need the factual, the possibilities and the values is shared. The only knowledge missing to enact the process is the boy's knowledge that mother needs 5 apples. This is therefore the message she gives him: „I need 5 apples; will you go buy them for me?“ The communication finishes the triggering integration. This is exactly what happens in a functioning LG.

Determinism: According to deterministic social viewpoints no real possibilities exist; the social world is determined, and the actors have no choice. However, language expresses the possibilities beyond any reasonable doubt as things people can do: one can walk, eat, sleep, sing, talk, read, take an exam, become a politician, get a job, be married, watch TV, buy a PC or 5 red apples, etc. These are things people can do. They are possibilities. The possibilities are widespread and common, although they depend on the situation. They operate in countless LGs in human practices. To deny their reality is absurd. As a matter of fact, the very construction of our worldview is that of a world in time and space. The positioning of ourselves in space is a presentation of ourselves in a world of multiple alternatives - you can go, look, dance, right or left, you can talk with the person to the right or to the left or in front depending on who you want to relate to, etc. And from any given standpoint, there is a way to any place on habitable Earth. Spatial cognition opens the world of possibilities. From an outer-world perspective everything may look determined, but that is not really relevant to the perspective of a living human actor.

The integration theory of action and reality construction implies that the meaning of a message has a threedimensional level of complexity. Some aspects of this complexity are normally presupposed situational knowledge of the participants. It is the missing part that is conveyed in the messages of the operating LGs. In situations that do not aim at realising specific actions, such as in learning, training or small-talk, people exchange and acquire a lot of situational information that may function as background situational knowledge.

The skills and self-confidence necessary to participate in LGs is important and normally assumed. However, people have very different communicative skills. Some have strong skills; some have poor skills. This must be taken into account. Many disasters in practice happen because somebody in the game was unable to convey a message with sufficient force for others - mostly superiors - to take notice of them. For instance, such an absurd disaster as an airplane crashing because the pilot, communicating with the control tower for a longer period, is unable to make the tower aware that they are running out of fuel. Such serious communicative errors may be a weakness of an employee, but it is also a fault of her superiors. The superior defines the climate of communication and signals what and when she wants to hear something or not. Overall this problem may be the result of a dysfunctional culture of communication.3

\footnotetext{
${ }^{3}$ The theory of 4-dimensional integration implies that our analysis replaces the semiotic triangle of reference: "symbolreference-meaning/thought” (Ogden \& Richards 1923) with the integration of the four dimensions: while symbol and reference correspond to communication and reference, the meaning or thought is replaced by possibility and value that are necessary both of them.
} 


\subsection{Meaning as Reference}

Wittgenstein's notion of meaning as use is contrasted with the notion that the meaning of an expression, word or sign is what it refers to. The question: „What is an X“ can be answered by pointing at an X. If the boy asks his mother: „What is an apple?“ she might answer the question by pointing at an apple and saying: „That is an apple.“ To elaborate, one might say that the meaning is not the apple but the idea or concept we have of an apple. But in order to get such an idea we should like to see a few apples, bite into them and taste them. The appearance and the taste would identify the apples, and we would have a concept of what an apple is and thus understand the meaning of the word. The appearance and the taste would count as criteria in this definition of an apple.

This relation between observation and meaning is considered the basis of scientific or scholarly approaches to meaning and thus acceptable notions, which dismisses as unscientific concepts or ideas with meanings that could not be defined by observational criteria. This idea led to the verification theory of meaning known as logical positivism, which claimed that the meaning of an expression was a specific set of elementary observations, the basic data form our senses, the so-called sense data, and that this set of sensory observations would prove the existence of a given phenomenon. The meaning of the word "apple" would be the observations of its colour, shape, smell and taste, which would prove that something is indeed an apple. This theory has a certain logical atomism.

Despite a certain intuitive appeal to many scientists, the theory has been criticised because it turned out that it seems impossible to produce any viable definition of any concept in accordance with this idea. The elementary sense data seems unidentifiable, and it seems impossible to translate the meaning of any ordinary concept to observational data in this way. That said, we still are bound to identify the phenomena through observation. For instance, a more holistic, gestalt-based approach to perception initially appeared more convincing. Nevertheless, the verification principle inspired methodologies to produce social questionnaires by analysing complex concepts to a set of more elementary phenomena, that somewhat defined it, and which then were used to formulate the elementary questions. By calculating the answers, one could re-aggregate the information and draw conclusions on the complex matter.

Although we cannot reduce meaning to reference, the function of reference is essential. We are very much communicating about an external surrounding world and not only about inner phenomena. This realism is used to mark the difference between the factual and the non-factual, between our knowledge of the world and our presumptions, hopes, beliefs, guesses and sheer arbitrary postulates. It is also a guarantee that an actor-world relation does exist and is not mere imagination. On the other hand, this has posed problems concerning how to explore internal subjective phenomena. Modern psychology and brain research seem to open up much of the content of our internal black box.

\subsection{Meaning as Thinking}

A different approach to the basic function of language and thus the meaning of meaning is the theory that the core function of human language is the ability to facilitate thinking as advocated especially by Noam Chomsky (numerous publications. See for instance in Chomsky 2015). According to this view, human language is especially designed to create and promote thought - not communication. Language can be used for communication but according to its design that is not its core use. Our language is to some extent even counterproductive to efficient communication. But it enables us to think freely and creatively. Our stream of thoughts can automatically adjust to changes in environment and constantly make us approach situations in a reflective way.

\subsubsection{Speaking with oneself}

In this perspective, by far the majority of language use is tacit. It goes on as a reflection in our heads all day long. Since most words do have references, the reflection may mirror reality issues more or less realistically. Thus, the need for basic references to external realities is not rejected (cf. Wittgenstein's argument against a logically private language, 1953 e.g. §342). We are not rejecting a realist framework.

The tacit process of thinking may be considered a special form of communication. It is a variation of ,talking with oneself“", which one may do internally or out loud. Doing it out loud has the advantage of objectifying the thoughts so that one hears them as if somebody else had been talking. Such projection of private thinking has long time been supported by pencil and paper and recently greatly enhanced by personal computer systems. Consider the process of sitting thinking in front of the computer: The fingers throw the first idea down on the keyboard and there it stands on the monitor. The actor looks at the monitor, seeing her idea and pondering. Then she gets a new impulse and additional ideas fly out of the fingers and up onto the monitor. Some of the old ideas may be corrected others survive. This is a creative process: the ,spontaneous ' high capacity reflection produces the first idea. Then her critical logic evaluates it, analyses it, finds flaws and missing parts and then her creative capacity puts on a new layer of ideas and so on. The process is driven by some goal. The goal expresses some of her values. It defines when the process is finished. And the 
process is guided by her values concerning the quality of the work. The more ambitious the goal, the larger the work. Similar things take place in practical training. For instance: How to play a ball game effectively? This entails further details: how to move, how short or how long to make the steps, how fast, where to look, etc. Such reflection goes on when developing new skills. This learning may not be guided by a tacit - or spoken- dialogue with oneself. However, the more complex the process is, the more helpful it may be to guide the process by internal reflection, by formulating the goals and the steps towards reaching them.

Chomsky compares prehuman and human language by claiming that the animal languages are responses to stimuli - stimuli from senses or from inner states. Thus, they communicate for instance the presences of danger or desires for mating, etc. The special quality of the human language is that it is not bound to this kind of communication.

Traumatic events or complex trauma may be detrimental to thinking. It may block thinking or produce rumination due to shock and fear. Such environmental exposures restrict the human nature in unfolding and are harmful- no matter whether it occurs early or later in life, whether at home, at school, at a workplace or at an institution. It is damaging to one's health.

The focus on language as instrument for thinking illuminates the PC idea that a way a person can find out her subjective personal values is by observing the way they show themselves in the person's emotional reaction to events. For instance: if something makes a person angry some of his values have been challenged, if something makes a person happy then some of his values have been appreciated etc. Whereas the connection between the stimuli and the response in a primitive animal language may be innate, the human emotional response is based on a process of experiencing and learning through which the person acquires subjective values that eventually control her emotions. This internal learning process of connecting values with emotions involves a cognitive side which is provided by the process of internal thinking, which in turn is supported by our language. People think about things and this has consequences for their formation of themselves. Thus, human emotional reactions may seem spontaneous because they display the working of a habitus that is the result of active reflection and not a mechanic response.

Thinking or the reflective process creates a sophisticated cognition of the world. While our cognitions starts by relatively simple perceptual identification, reflection produces a different cognition of things. In addition to the identification based on something's appearance (the ,sense data'), we construct a concept of what tings are. What they are is not directly observed. Direct observation is used to identify things, not to tell us what they are. What they are depends on the possibilities and relevance (values) they possess for us. For instance, I look at a thing and it looks to me to be a smartphone. What does a smartphone look like? Something like: A small flat rectangular thing with a size fitting to a hand. But it is not the appearance with which we identify it, that which makes it a smartphone. What makes it a smartphone is its capabilities. The appearance works well in practice to identify things, but appearance may mislead. A toy-gun may resemble a real gun. They may have the same appearance. But the toy-gun is not a real gun. In the end, the only way to demonstrate what it is, is by using it and thereby proving that it can or cannot do the things that a phone or gun are supposed to do. Only by demonstrating the object's capabilities can I prove that it is a smartphone or a real gun.

\subsubsection{Cognitive layers and habitus}

Thus, our concepts evolve all the time. Layer after layer of knowledge is integrated in our conception of the world which influences all our concepts. They evolve especially through thinking. Ordinary use of things makes us better able to apply a given concept (more on cognitive habitus Nørreklit 2020). Most LGs use the concepts involved and could not take place without the concepts. Thinking has the ability to develop the concepts. In the beginning our concepts identify things by their appearance. Later, when our skills develop, we identify them through their use, i.e. the action-possibilities they possess. One might even develop an Aristotelian type of metaphysics to handle things. At a still deeper level, things may be conceived from a physical ontology such as matter and energy as in classical physics ending with a quantum theoretical perspective of things as probability waves. These different ontologies evolve while a variety of practical, ecological and other concerns evolve and become integrated in our cognition and thus influence our concepts. Thus, the concepts and the cognition as a whole are habitus. People have very different concepts of the same things. They are, however, able to communicate about things because there is an overlapping basis in appearance. Although appearance may become more sophisticated as a concept evolves the original common primitive appearance of, say, a phone or a gun is still part of the individual habitus. The development of the cognitive habitus requires a lot of practice. This applies to the theoretical skills as well as the practical skills. And, as we have recognised, there is a connection between these two aspects: the training of practical skills is guided by the ideas we have and motivating values. We have a value-driven process of development. The more these values are intrinsic to us, the more they are our own values, values adopted through our experience, the stronger our integration of values and possibilities will be.

Human individuality is thus not only a matter of biological-social development in a space-time continuity in a certain world. It is also produced through thinking, which gives the person a personal stand and mastery of a field in a way that cannot be achieved otherwise. The person has individuality due to her personal habitus, which is not only a 
cognitive habitus. Reflection also involves reflection of the relation to her feelings, her values, her ethics - i.e. the person she is. Reflection wires her personality in a personal and qualified way.

\subsubsection{Reflection and possibility}

Whereas the referential function is the basis for the factual dimension, the thinking and reflection is the basis for the development of cognition of possibilities. For possibilities to be real and not only personal hopes, they need to be tested, so that the personal conceptions match the real possibilities. The world may always have more possibilities than the ones we know. On the other hand, what possibilities we do have is a question of what we know, and what technology we have produced. Poor thinking means that the work of possibilities is not explored or thoroughly researched. Thus, thinking has different qualities: how thorough it is, how stringent, how creative, how logical, how radical. The ordinary language of communication provides a string of concepts that automatically indicate a range of possibilities that may be factual, as mentioned already: verbs tell us what we can do, the concept of things tell what one can do with these things, etc. The thoughts that produce awareness of these possibilities have been made and are part of our knowledge. By thinking, we can construct new and more advanced or more satisfying possibilities out of the factual possibilities we already have. By not thinking we miss those opportunities. If we are controlled by fear, we may restrict ourselves and avoid even considering such possibilities.

Thus, the dimension of possibility concerns the actor-world relation where the skills, which are based on reflection and training, mirror dispositions that the actor can control through her skills. This gives the actor a certain control over events in time. The future is not just something coming and hitting the actor as inevitable fate, but rather something the actor is able to influence to a certain degree.

The dimensions of integration are tied to aspects of meaning. The factual dimension is related to the referential function. When we have sufficient evidence that the reference is real, then we are concerned with factual things. We may be mistaken in our judgment of the evidence and thus the claim that something is a fact may eventually be disproven. But as long as the evidence satisfies our criteria for good evidence, we are justified in calling it a fact. It makes it a justified knowledge claim but not an absolute one. The knowledge claims are defeasible.

Possibilities are not directly observable. Thus, they are based on thorough reflection - i.e. on thinking, imagining, analysing, and testing. There are all kinds of possibilities such as: logical, imaginative, theoretical, economic, organisational, political, practical, technological etc. We notice that the various types of possibilities are related to various disciplines, theories and practices. The basic construction of a possibility is imagination, and especially imagining things differently from what we perceive. The idea of difference, of being not like that which is observed, produces a horizon of logical possibilities. What interests the actor is how the possibilities can be integrated with the factual, i.e. become factual possibilities. While our language already has a lot of concepts for such integrated possibilities which we learn by learning the language, as we have seen, it is for qualified reflection and research to develop new advanced possibilities.

Finally, we have the experience of feelings as reaction to situations as the basis for identifying the values. The values are driving forces. Our interests and activities are driven by our values. They make us interested in the phenomena we refer to, and analyse their properties and thus the possibilities of things.

To analyse specific types of possibilities we construct so called symbolic languages, i.e. symbolic systems with stringent logic and symbols with unambiguous meanings. Such symbolic language promotes analysis of special phenomena and is a working instrument of technology and science. It pays a price in that it abstracts from driving values. They are not sufficiently integrated in this language. Formal logic and mathematics, for instance, are formal and thus do not reference any facts, possibilities or values about the world. Physical theories do have reference to the universe but abstract away from references to value and communication. Economic theories also integrate general values but are still lacking integration of the communication constituting the social factory. That is why when symbolic languages are used, then they are embedded in a language games in which it is mixed with ordinary language and integration is restored.

\section{The double loop Understanding}

The aim of this analysis of the process of understanding is to point out the need for an understanding that involves the actor-world relationship. In what we call a ,single loop understanding ‘, understanding refers to an endeavour to understand the phenomena in themselves. This produces practical problems as well as theoretical problems and should be replaced by a model that incorporates the meaning of the phenomenon to the actors, cf. figure 2. To achieve this and solve the problems the ,double loop understanding‘ (Nørreklit 2006 and 2012) is introduced. 
Understanding and meaning are complementary phenomena: We understand the meaning of things people say and do. But we may also understand why things happen, i.e., we can somehow explain why they happen. Thus, understanding and explanation are also complementary, although different. Wittgenstein addresses the issue of understanding in several LGs and explains understanding as the ability to participate and continue in an LG, responding adequately to the input from the others.

In an LG, understanding enables interpretation of the situation and signals of the other correctly. Since we are not mind-readers, this is accomplished through communication. Communication should provide an actor with the insight necessary to achieve the understanding of her game's co-actors, which may be a simple or a complex process. Since actors cooperate, understanding is supposed to be mutual and thus not only a subjective but also an intersubjective and organisational phenomenon.

To analyse the type of communication which produces mutual understanding between actors, the concept of dialogue is used. An environment in which there is no place for a dialogue has no room for development of mutual understanding and is therefore prone to suffer from problems of insecurity and errors.

The dialogue takes form of a so-called circle of understanding (hermeneutic circle). This is a dialogue though which the participants try to understand what the other means though an ongoing exchange of questions and answers (cf. Gadamer 2004). Imagine that A and B discuss a certain topic. Both of them have their specific knowledge - a horizon of understanding or pre-understanding - which gives them a certain although different understanding of the topic. 4 The difference causes the actors to understand the topic differently. Thus, problems understanding each other may occur. We shall distinguish between a single and a double loop analysis of the dialogue that aims at solving this problem. The single loop works if people trust and understand each other's perspectives. Otherwise it produces rather unproductive discussions.

\subsection{Single loop understanding}

The process of understanding is a dialogue in the form of an exchange of questions and answers about the topic through which one person tries to understand what the other means and vice versa until both of them understand what the other means. The exchange of questions and explanatory answers form the hermeneutic circle. The process of question and answer is looping in this- single cycle. The exchange works by widening the participants respective horizons and ends with a fusion of horizons though which A and B achieve an identical understanding of the topic. An actor enters a dialogue with a specific individual horizon or pre-understanding of the topic and comes out of it with a wider and shared horizon.

The single loop intends to represent a human perspective, different from explanatory analytical perspectives. The endeavour to engage in understanding is a kind of paradigm that some consider humane, as well as distinct from the alternative explanatory approaches. This may however be rather misleading. For one thing, the single loop practice does not necessarily enable an actor to understand the other. On the contrary, it abstracts from the other. A single loop participant does not aim at understanding anyone, not even herself. In the single loop approach, to achieve understanding of people they first must become the topic of the dialogue, which then, however, may seem like a kind of therapeutic endeavour. Also, if the other is made the object, then the understanding is often used to develop ways to control the other since it is easier to control them if one understands them.

\subsection{Problem}

The single loop approach sounds like a straightforward LG that should easily produce results. However, we often see dialogues that turn into fierce discussions that are seemingly unable to come to an end. It may continue for generations. Imagine, for instance, a debate between a qualitative (A) scholar and a quantitative (B) scholar. A: „Without proper qualitative studies, no one knows what they are talking about.“ B: „Science is about analysing numbers and especially correlations - qualitative studies never produce adequate basis to define any correlation." This debate has lasted generations and is still raging. From a rational point of view, it seems easy to draw a few sound conclusions: Both A and B have a point. How can such debate be unsolvable? Especially because the debate is mostly amongst scientists, presumably clear-thinking people? The discussion should easily produce a wonderful fusion of horizons - but that does not happen. The single loop approach to understanding is missing something.

One problem may be that there may be a social dogma demanding an actor take a position. That is often the case. Even research institutions sometimes behave as institutions for indoctrination. However, this is in itself no reason why A and B should not be able to produce a common understanding when communicating eye-to-eye. Thus, let us assume

${ }^{4}$ While Gadamer distinguishes between horizon and pre-understanding, I want to focus on the difference between single and double looping. 
that there is no organisational pressure. Even in this case, we can imagine LGs where A and B fight for their respective position without making any progress.

The problem in the LG between A and B is that it is not real dialogue. A and B are focused on the topic and each of them is trying to prove that she is right and the other is mistaken. That is not a dialogue. They pretend to take each other seriously, but they do not. Neither A nor B are concerned with the question of why the other does not understand her, but rather both continue to understand the topic differently. „Why can she not understand me?“ implies there is something wrong with the other - not with oneself.

The single loop understanding focuses on understanding the object/world. It abstracts from the relation between actor and object/world and conflicts therefore with a PC perspective. As soon as we focus on the relation between actor and the topic, then we re-introduce a focus on reality construction: the actor-world relational complex. We can interpret meaning of a phenomenon as the role it plays in this complex. So, what is it in the relational complex that keeps dividing A and B? We may find it in the actor's experiences. For instance: Assume that A has solid experience that she is doing well in qualitative approaches and thus sees that as a way to success for her, while she has had bad experiences with quantitative disciplines, in which she scores poorly. Thus, for A the discussion with B is much more than a discussion of a neutral topic. It is a discussion of whether A shall endanger her success and risk becoming a failure by admitting the need for working quantitatively, where she knows she is a failure and no frontrunner. She feels deeply uncomfortable with the idea that she should turn her understanding into math. She doesn't show this fear in the discussion. She pretends that she is objective although her fierceness shows otherwise.

Imagine the opposite case applies to B. She is good in calculation and deductive procedures. However, when relating it to the complexities of life she feels dizzy and cannot feel the ground. She is not comfortable reflecting using ordinary concepts, but in formal structures, where numbers easily apply, she is a fish in the water. Thus, she is also defending her very existence from failure by sticking to her position on methodology.

Now it is obvious why in the single loop there is no progress despite a fierce but apparent dialogical circulation going on. The discussion is not a discussion about methodology per se but about what the methodologies mean to the participants. It is here that meaning is not only intersubjective or objective, but it also becomes existential.

To describe this, I will adjust the notion of pre-understanding. In a single loop, pre-understanding is the set of knowledge-glasses through which the person views the topic before she enters the dialogue. It is a lens in the back of her head through which she sees the topic. The dialogue would then change her understanding until the participants have a common understanding. Now we see that the pre-understanding is something else and much more. It is not only glasses with which to observe the world, it is a shield, and it has a set of weapons with which to defend the actor, keep the actor out of danger and enable the actor to achieve success and victory. It is a shield she holds in front of her to protect her. It hides the actor and may even make her seem invincible. For instance: A wants to be protected against quantitative methodological demands and B wants to be protected against demands form qualitative methodologies. None of the actors can give up their position. It is not a dialogue but an existential fight. It is suicidal to give up, thus the fight can continue.

\subsection{Double loop understanding}

While aiming at achieving a common understanding of the topic only is a „single loop“ understanding, a „double loop“ understanding“ process aims in addition - and from the very beginning on - to identify and understand the special pre-understanding of the other and what role it plays in the game. 5 Instead of hardening the positions through irrelevant repetitions one engages in a second loop in which one searches for ways to understand the other person: "why does she think or behave as she does?” "what might scare her?” "what makes her feel uncomfortable with my interpretation?” The inner life of the other contains more than the logic and factual knowledge which is outwardly expressed. It also contains her values, which she protects. She is fighting, so what is it that worries or scares her and has ignited the fear or anger that makes her fight? If there was no worry then our discussion would make both of us wiser, but that does not seem to happen. It is not difficult to make qualified guesses, and use them to carefully calm the other. For instance: „You don't need to worry about the qualitative (quantitative) side. That is not your job.“ If this was her real worry then such comments - indirect communication - may gradually change the course of the dialogue and make it more productive (for indirect communication see Kierkegaard 2009). Thus the ,second' loop reflects the reason why, for instance, an actor protects her interpretation in an intransigent way and seemingly destroys the quality of the dialogue. It is important to our understanding that this reflection takes place. It is a natural reflection that actors undertake when they do not know their partners or when they feel uncertain about whether they understand their partner. It is not natural to bypass the initial curiosity or emerging concern: who is this partner? why does she behave like this? In most cases the reflection should be part of the dialogue, making it loop around the first questions and answers. Often this may not be

\footnotetext{
${ }^{5}$ Originally the theory was called "Doubled Hermeneutics”. To avoid confusion with Giddens theory of double hermeneutics, I re-baptised it to

“Double loop Understanding or "Double Loop Hermeneutics” - inspired by Argyris notion “double loop learning” (Argyris 1991).
} 
possible, but it can occur as a tacit indirect dialogue. The double loop enables the actors to understand each other as human beings and get control over the situation, which contributes essentially to reducing the fear and resistance, and opens the willingness to cooperate with the other's perspective. This improves the workings of the social factory producing friendliness, trust, skill and cooperation.

The double loop introduces LGs which are very different from those initiated by single loop understanding. They address the other as people with a concern for the other's position and situation - i.e. in the LG, in the dialogue, respecting the other as a person fighting for a reality construction that works for her. Recognising that she is fully entitled to do that, that this is a human right, recognising in your double loop that you support that right: these things enable you to play a very different and much more fruitful game of understanding with her. Without a double loop interpretation, we cannot understand the meaning, i.e. the role the expression plays in the reality construction. Without it people live in LGs stripped of recognition. Double loop understanding involves recognition and respect.

Understanding the actor and the topic, as well as the dynamics of their relation, is understanding the inner workings of our relations to the world. For each possible relation an actor may ask: is this the route I should take? Is this topic (method, partner, book, apartment, job etc.) something for me? If one cannot decide what to choose, life may come to a standstill. And for some people one thing may be the ideal way while for others it is not, as in our case with A and B. Since the possible relations are constantly on the move and changing, the process of evaluating which way to go is always nearby. However, it is important that an actor can make important and lasting choices. Only through the endurance of the choice or its outcome will the actor be able to develop real quality in this relation. This applies to the relation to other people or to job performances. For instance: Having decided that qualitative method is the way for A, while quantitative method is the way for B, they can then start becoming masters in their special methods and make valuable contributions. It is often very difficult, however, to find out which way really is a good way. The world is unpredictable, and an actor may not really know what capacities she has.

Having reached the role a phenomenon plays in the actor-world relational complex of reality construction as the real issue of understanding, we conclude the analysis reminding that the relational complex involves analysis of the integration of the four dimensions.

The difference between the two interpretive approaches mirrors difference in the actor's relational entanglement such as their attachment, the detail and engagement of the relation and the attitude towards world and other.

The attitude towards the other and the world as object - reflecting the single loop approach - imagines a person a as pure subject, i.e. as not and actor but a reflector or observer ,outside the world‘. This apparently individualist position, standing alone observing everything, is of course inconsistent with human experience. Observation presupposes conscious activity and thus an actor. On the other hand, there are some and advantages of this attitude such as self-control, ability to approach things professionally, and so on. The losses related to this attitude is loss of belonging somewhere, i.e. a loss of deeper relations. The loss of existential meaning because one has disengaged oneself existentially from the world. This attitude of detachment should therefore be only a part of a wider palette of attitudes.

The attitude towards the other and the world reflected in the double loop approach may seem to strengthen relationships and cause greater entanglement in the world of the other. There may be a greater sense of mutuality and thus of social belonging. However, the single loop is an integral part of a double loop we see a palette of attitudes emerge there.

Both approaches are important, and both positions are alive in different language games. The double loop needs the single loop because it is a part of the double loop. There are productive practices where we apply our knowledge, and there are practices where we are focused on restricting our activities in order to enable new types of observations. To reject the single loop would result in a solipsist idealism where all reality is about the relation between the actor and her pre-understanding, which is to say the world would simply be reduced to pre-understanding. Thus, the double loop approach to understanding is inevitable. The double loop understanding studies the actor-world relational complex, i.e. the construction of reality. By focusing on integration one can identify weaknesses and illusionary elements of the construct.

In conclusion the single loop practice produces a culture of no understanding of any participants of in a dialogue, i.e. an ,cold', unemphatic culture. It analyses the referent, the topic as object only. However, to achieve full understanding it should analyse the role the topic pays in the reality construction of the actors in order to understand the actor-topic relation - it needs to understand the actor, the topic and the relation between the two which is what role the relation plays in the overall reality construction of the actors.

\section{Conclusion}

The article starts outlining some basics about the theory of language game as the social factory and basis of cooperation and division of labour, as well as the basis of pragmatic constructivism as the model of integration and the 
model of the actor-world relational construct. Then we unfold the interpretation of meaning involving standard approaches to meaning to illustrate how in combination they make integration come alive. Finally, we introduce the dialogue and the process of understanding and guide the process of understanding away from a purely objectified model, i.e. the single loop, to a relational approach, i.e. the double loop, matches PCs relational approach to reality.

\section{Appendix: The Is-Ought Problem}

One of the problems in moral philosophy originates from an empiricist approach that considers empirical facts as the foundation of our concepts. A consequence of this approach was a form of reductivism that made statements about duties and moral evaluations without rational foundation. The problem is famously stated by D. Hume. (Hume 1739-40 seen1.1.27). He argues against the idea that any rationalism is able to prove moral duties. All these attempts fail. First, he observes that all these systems of morality proceed with string of apparently sound arguments. But, at some point in the argumentation they make an almost innocent and unremarked transition from premises about what ,is“ to conclusions about what “ought” to be. Clearly, such deduction is invalid. This argument, sometimes called Hume’s guillotine, establishes the is-ought gap, i.e. a sharp disintegration between the factual (is) and the normative (ought). No matter how many factual premises one makes, one cannot validly draw a normative conclusion.

The PC based theory of meaning does not, however, support this kind of disintegrated view on the formation of concepts in which facts and obligations, the "ought” and the "is", are separated. On the contrary, values must be integrated with facts, otherwise there is no LG and there is no reality. There is a world, but we cannot construct a human way to be in it. And, plenty of ordinary notions exist that obviously have a factual as well as an evaluative side and thus automatically display some form of integration. For instance: „torture“. Torture, for instance, is strongly negatively loaded, but at the same time it has descriptive elements that allow us to identify behaviour as torture. These elements may vary in different cultures, but without them the word would have no meaning.

Hume's argument is rejected by our very participation in LGs. In an LG there is a division of labour. Without such division there can be no game. The divisions give the participants a justified expectation that others a special task one role or task, which is their obligation or duty to fulfil and that they endeavour to fulfil it. Participation in the game means that one has accepted the duty. The game is a system of mutual dependencies and it is not up to the individual player to arbitrarily change or leave the game. Leaving and entering the game is subject to conditions in order to avoid damage to the players. By entering the game one has accepted the duties to play the role and follow the rules. 6

The rationalist idea that one can prove duties from a list of ,natural' facts is from the very outset a misunderstanding. Duties are relative to the social setting. The system of duties varies in different societies as the specific duties vary in the different LGs. Thus, duty is a social concept, already implying a certain element of community. There is no society without duties and obligations, and vice versa.

Where the boundary between the societies and communities are, or whether there are any such boundaries, is a serious ethical issue. The rules and thus the duties apply to those within the community or society. People outside the boundary may thus be treated differently. Thus, what is counted as murder inside a society may be considered heroism in war or conflicts between different countries. From a philosophical point of view, we need to realise that we have but one society on Earth. What we do with the living conditions affects all. The discriminatory ideology of dividing people/states/cultures between the good (us) and the bad or evil (the other) is that which is evil. It is a creates a state of natural war which continues to produce immensely destructive wars around the globe, in which the ,good guys ' - us attack and kill the ,bad guys‘. This is the evil of the imaginary good. It must be replaced by the rule of law. It is an attempt to split a world that is already united by the ability to understand, communicate and organise cooperation across the globe. The god-bad or black-and-white divide is a dangerous mental disease which contradicts the modern condition.

\section{References}

Argyris, C. 1991. Teaching Smart People How to Learn. Harvard Business Review. May-June. Chomsky, N. 2015. Language and Thought. Youtube Channel: Chomsky's Philosophy. 20.01.2015.

Foot, Philippa: Moral Dilemmas and Other Topics in Moral Philosophy, Oxford: Oxford University Press, 2002

Gadamer, G. H.: Truth and Method. London. Continuum International Publishing Group. 2004.

Hume, David. 1739/40 (1975). A Treatise of Human Nature. Oxford: Clarendon Press.

Jakobsen, Morten, Johanson, Inga-Lill, and Hanne Nørreklit (Eds). 2011. An Actor's Approach to Management: Conceptual Framework and Company Practices. Copenhagen: DJOEF.

\footnotetext{
${ }^{6} \mathrm{Ph}$. Foot used a Wittgensteinean approach to meaning to counter the reductivism behind the guillotine. (Foot 2002).
} 
Kierkegaard, S.: Concluding Unscientific Postscript to Philosophical Fragments. 2009. Cambridge University Press. Nørreklit, Lennart. 2006. The double hermeneutics of life world. A perspective on the social, dialogue and interpretation. Aalborg University. vbn.aau.dk/ws/portalfiles/portal/18718783/5-Double-Hermeneutics.pdf.

Nørreklit, Lennart. 2011. Actors and reality: a conceptual framework for creative governance. In An Actor's Approach to Management: Conceptual Framework and Company Practices, edited by Morten Jakobsen, Inga-Lill Johanson, and Hanne Nørreklit, 7-37. Copenhagen: DJOEF.

Nørreklit, Lennart.2012. The double loop hermeneutics and emphatic aspects in social work. Dialogue in Practice pp 151-158. IUC Dubrovnick. dialogueinpractice.net.

Nørreklit, Lennart. 2014. Reality as a Construct: Outline of a Pragmatic Constructivist Perspective. PROPRACON Vol 3. No. 2. propracon.com

Nørreklit, Lennart. 2017. Actor-Reality Construction in Nørreklit, H. (ed.) A Philosophy of Management Accounting. NY. Routledge.

Nørreklit, L. (2017). Actor-reality construction. Chapter 2 in H. Nørreklit (Ed.), A Philosophy of Management Accounting (pp. 23-72). New York: Routledge.

Nørreklit, Lennart. 2020. Paranoia and Control. A narrative about the Social Factory. In R.-D. Hepp, R. Riesinger: Hyperprecarity. Social-Cultural Transformations in European Societies. Wiesbaden. VS Springer. (Forthcoming).

Ogden, C.K. \& Richards, I.A. 1923. The Meaning of Meaning.

Wittgenstein, L. 1953. Philosophical Investigations. Translated by G. E. M. Anscombe. Oxford: Basil Blackwell. 